\title{
WEAR-RESISTANT SURFACING WITH FEEDING OF NANOPOWDERS TO WELD POOL
}

\author{
V.D. KUZNETSOV and D.V. STEPANOV \\ NTUU «Kiev Polytechnic Institute» \\ 37 Pobeda Ave., 03056, Kiev, Ukraine. E-mail: v.kuznetsov@kpi.ua
}

\begin{abstract}
Experimental studies of wear resistance of deposited metal, produced with feeding of nanooxides to weld pool, are of interest, when searching for new methods to guarantee the high wear resistance of deposited metal for items exposed to friction in service. The paper presents the results of testing wear resistance of deposited metal of 40Kh13, 25KhG2S, 300Kh28M type, modified by aluminium, titanium and silicon nanooxides through the weld pool with different schemes of their feeding. It is shown that nanooxide feeding to weld pool leads to a noticeable increase of deposited metal wear resistance. 13 Ref., 8 Figures.
\end{abstract}

$\boldsymbol{K} \boldsymbol{e} \boldsymbol{y} \boldsymbol{w} \boldsymbol{o} \boldsymbol{r} \boldsymbol{d} \boldsymbol{s}:$ arc surfacing, wear resistance, nanooxides, nonmetallic inclusions, structure

Deposited metal properties are determined by the specified composition of alloying elements and structure. Requirements to metal composition and structure to ensure the required values of its wear resistance are specified, depending on service conditions. The main results of investigations in this area are generalized in [1, 2].

Over the recent years a significant role of nonmetallic inclusions, as a factor controlling cast metal structure and properties, has been noted in publications. The main part of studies was performed for welding low-alloyed steels. Here, precipitation of such inclusions in the form of oxides, carbides and nitrides in weld metal was considered to be the result of chemical bonding of the respective elements during solidification, whereas the inclusions proper, both of up to $1 \mu \mathrm{m}$ size range, and close to nanosize range, were given the role of inoculators [1-6]. In other cases, formation of nonmetallic inclusions was the result of feeding nanooxides or nanocarbides into the weld pool [7-9]. A positive influence of inclusions of a certain composition, dimensions and distribution density on weld structure and properties is noted in all the cases.

Information on their influence on deposited metal wear resistance is limited, although the available experience of applying both nanooxides in plasma surfacing [10] and nanocarbides in electrode coatings [11] points to good prospects for their application in surfacing processes.

The objective of the work was experimental study of deposited metal wear resistance at feeding nanooxides into the weld pool.
Different schemes of nanooxide feeding into the weld pool were used in the experiments. Nanocomponents were added to the weld pool in the form of master alloy after compacting and sintering of a homogeneous mixture of iron powders of $40 \mu \mathrm{m}$ particle size and nanosized powders of aluminium and titanium oxides $(27-41 \mathrm{~nm})$ with specified volume ratio.

Prepared master alloy was used as consumable electrode of a certain length and diameter, inserted into the slot before surfacing. Volume ratios of nanooxides established earlier for low-alloyed steel welding were used in these experiments $[8,9]$.

In other schemes, more readily adaptable to surfacing, the mixtures prepared in specified volume ratios, after their processing in a planetarytype mill, were first fixed by priming to avoid scattering, and were applied in a thin layer across the bead width for the entire length of the deposit. The same scheme was applied for feeding just nanooxide powders into the weld pool with recalculation of their weight fraction to weld pool volume.

For the conditions of metal-to-metal friction tribotechnical testing was performed in friction machine of CMTs-2 type by shaft-block scheme. $20 \mathrm{~mm}$ long and $10 \mathrm{~mm}$ wide samples were used. Disc of $50 \mathrm{~mm}$ diameter from U8 steel of hardness $H B$ 400-450 was applied as the counterbody. Testing conditions were as follows: pressure applied to sample $P=0.1 \mathrm{MPa}$; friction velocity $v=0.8 \mathrm{~m} / \mathrm{s}$; test temperature $T=20{ }^{\circ} \mathrm{C}$; test duration was $2.5 \mathrm{~h}$ with measurements taken every $30 \mathrm{~min}$.

Samples were weighed before and after testing in accurate laboratory scales with $0.001 \mathrm{~g}$ error. Mass wear was determined as the difference of sample mass values before and after testing. 


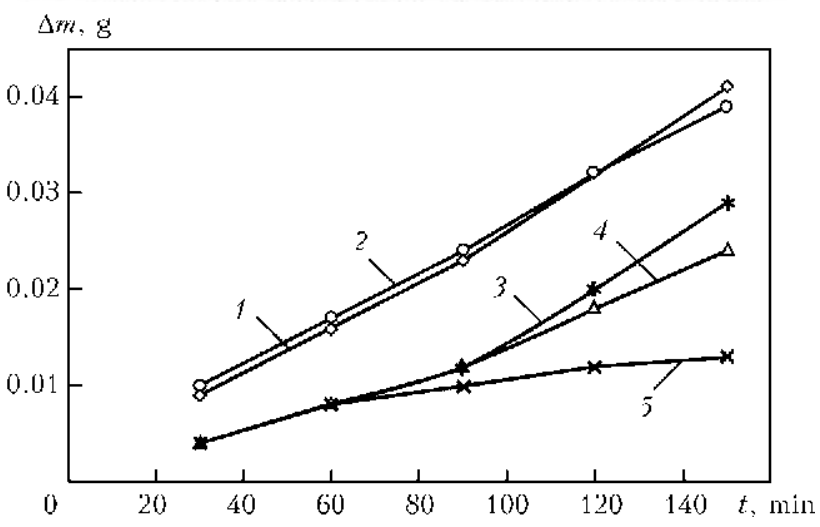

Figure 1. Wear resistance of metal deposited with PP-Np$40 \mathrm{Kh} 13$ wire with feeding nanoadditives through sintered master alloy: 1 - initial bead; 2 - with feeding of $0.5 \% \mathrm{TiO}_{2}$ to the weld pool; 3 - same, with $1 \% \mathrm{TiO}_{2}$; $4-1 \% \mathrm{Al}_{2} \mathrm{O}_{3} ; 5-0.5 \% \mathrm{Al}_{2} \mathrm{O}_{3}$

Testing for abrasive wear was performed in LKI-3 unit by measuring mass losses every $30 \mathrm{~m}$ of friction path. Electrocorundum of $14 \mathrm{~A}$ grade with $0.4-1.0 \mathrm{~mm}$ grain size was used as abrasive. Samples were tested at constant load $P=150 \mathrm{~N}$ along the total friction path of $480 \mathrm{~m}$. After every $30 \mathrm{~m}$ the samples were turned through $90^{\circ}$ to achieve uniform wear, and after every $120 \mathrm{~m}$ they were weighed in the scales to determine the change in mass.

To reveal the general regularities, beads were deposited using different processes and conditions. So, experiments on surfacing with application of $2 \mathrm{~mm}$ flux-cored wire PP-Np-40Kh13, recommended for metal-to-metal friction conditions, were conducted on steel St3, both in the mixture of gases $\mathrm{Ar}+28 \% \mathrm{CO}_{2}$ in semi-automatic machine $\mathrm{KP} 004 \mathrm{U} 3$ at $10.6 \mathrm{~kJ} / \mathrm{cm}$ heat input, and by an open arc in AD-231 automatic machine at $15 \mathrm{~kJ} / \mathrm{cm}$ heat input, and surfacing with $2.2 \mathrm{~mm} 25 \mathrm{KhG} 2 \mathrm{~S}$ wire of $09 \mathrm{G} 2 \mathrm{~S}$ steel was conducted in AD-231 automatic machine at $11.5 \mathrm{~kJ} / \mathrm{cm}$ heat input.

For abrasive wear conditions surfacing of steel St3 with $2.7 \mathrm{~mm}$ flux-cored wire PP-AN-180 (analog of flux-cored strip PL-AN-180) was also performed by automatic machine AD-231 at heat input of $12 \mathrm{~kJ} / \mathrm{cm}$.

Testing of metal deposited in welding in a gas mixture with PP-Np-40Kh13 wire showed ( Figure 1) that at feeding of nanooxides into the weld pool, metal wear resistance is increased at melting of sintered master alloy both in the presence of nanooxides of aluminium and of titanium. Here, mass losses in the case of application of $\mathrm{Al}_{2} \mathrm{O}_{3}$ nanooxide are smaller compared to $\mathrm{TiO}_{2}$ (compare curves 4, 5 and 2, 3). Maximum effect is observed at feeding of $0.5 \% \mathrm{Al}_{2} \mathrm{O}_{3}$ into the pool with mass losses decreasing from $\Delta m=$ $=0.042 \mathrm{~g}$ (initial bead, curve 1$)$ to $\Delta m=0.013 \mathrm{~g}$ $\left(0.5 \% \mathrm{Al}_{2} \mathrm{O}_{3}\right.$, see curve 5$)$, i.e. by more than 3 times. These data confirmed that similar to welding, at surfacing the fed volume ratios of nanooxides influence cast metal properties.

Microhardness measurement showed that at average value of initial bead metal microhardness of $H V$ 530, in the other cases microhardness decreased $\left(0.5 \% \mathrm{TiO}_{2}-H V 478,1 \% \mathrm{TiO}_{2}-\right.$ $\left.H V 460,0.5 \% \mathrm{Al}_{2} \mathrm{O}_{3}-H V 469\right)$, except for $1 \% \mathrm{Al}_{2} \mathrm{O}_{3}(H V 552)$.

Deposited metal microstructure consists of martensite with developed coarse-needle texture characteristic for the initial conditions (Figure 2, a). In the case of surfacing with $0.5 \% \mathrm{Al}_{2} \mathrm{O}_{3}$ nanooxide, a markedly smaller amount of martensite precipitate blocks with less developed needle-like structure (Figure 2, b) is observed. Another characteristic feature also is presence of, possibly, carbides and oxides along grain boundaries, which as a hard component promote an increase of wear resistance of such metal, alongside thinning of martensite precipitates. No correlation between hardness and wear resistance is observed in this case.

At application of surfacing scheme with powder fixing on the plate surface, aerosil (silicon dioxide) was further added, both in the mixture with iron powder, and in its pure form. Aerosil

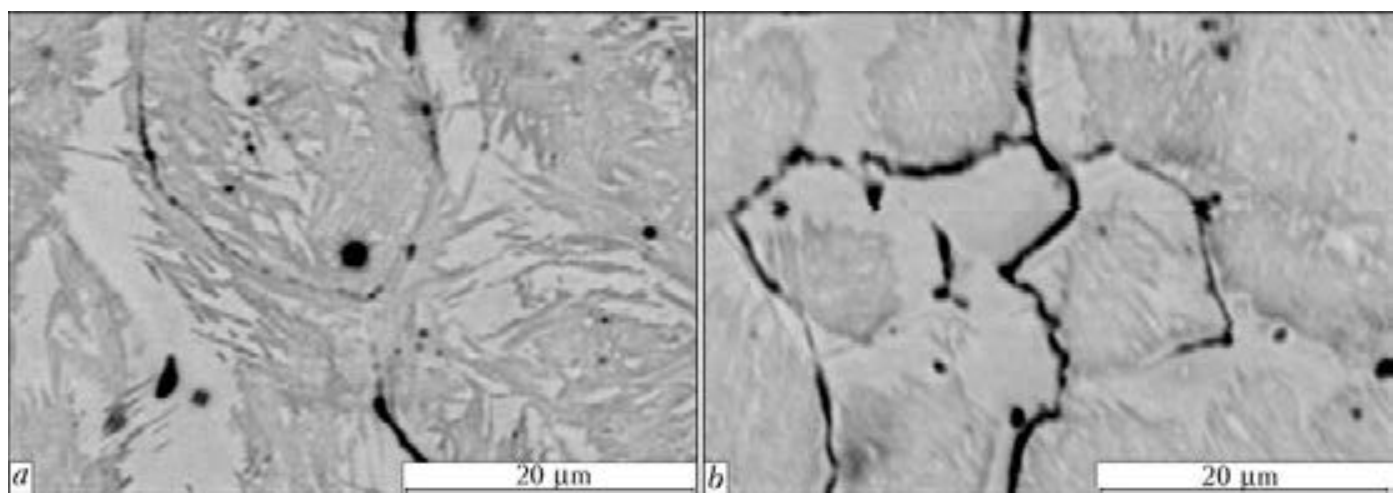

Figure 2. Deposited metal microstructure at nanooxide feeding through master alloy: $a-$ initial bead; $b-$ with $0.5 \% \mathrm{Al}_{2} \mathrm{O}_{3}$ nanooxide 


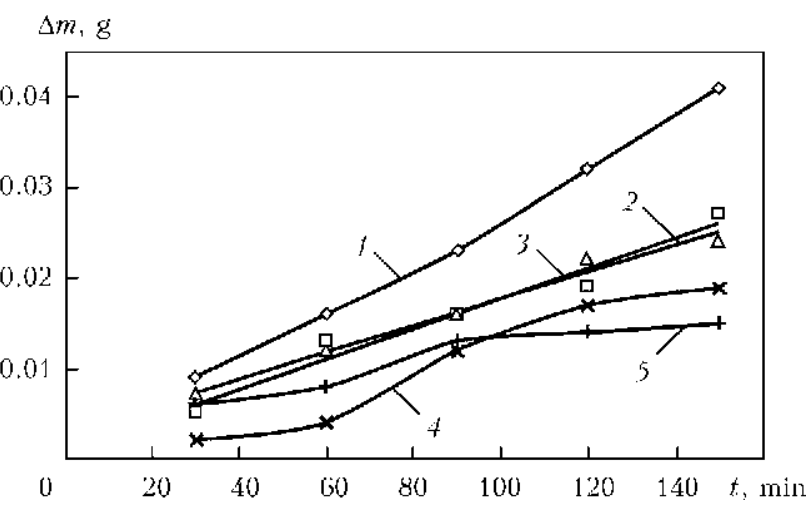

Figure 3. Wear resistance of metal deposited with PP-Np$40 \mathrm{Kh} 13$ wire with feeding nanoadditives through powder materials: $1-$ initial bead; $2-\mathrm{Fe}+0.5 \% \mathrm{Al}_{2} \mathrm{O}_{3} ; 3-$ $\mathrm{Fe}+0.5 \% \mathrm{TiO}_{2} ; 4-\mathrm{Fe}+45 \% \mathrm{SiO}_{2} ; 5-10 \% \mathrm{SiO}_{2}$

is manufactured on the commercial scale for preparation of various lubricants, paints and lacquers, for suspension stabilization. Considering several times lower density of aerosil relative to aluminium and titanium nanooxides, its volume ratios were increased, accordingly.

It is established that aluminium and titanium nanooxides in this case showed lower wear resistance (Figure 3, compare curves 2, 3 and curve 1 for initial bead), compared to feeding through sintered master alloy (see Figure 1) that, apparently, is associated with deviations from percent ratio and their incomplete absorption by the weld pool. Maximum wear resistance is observed in the case of application of powder of just silicon nanooxide. In this case, mass losses decrease from $\Delta m=0.042 \mathrm{~g}$ (Figure 3, curve 1) to $\Delta m=0.015 \mathrm{~g}$ (Figure 3, curve 5), i.e. by 2.8 times.

Testing of metal deposited by open arc with 25KhG2S wire showed (Figure 4) that both aluminium and titanium oxide promote improvement of deposited metal wear resistance (compare curves 2, 3 and curve 1 for initial bead), while mass losses in case of feeding $0.7 \% \mathrm{Al}_{2} \mathrm{O}_{3}$ are reduced 4 times. Maximum wear resistance increase by more than 6 times is observed in the
$\Delta m, \mathrm{~kg} / \mathrm{m}^{2}$

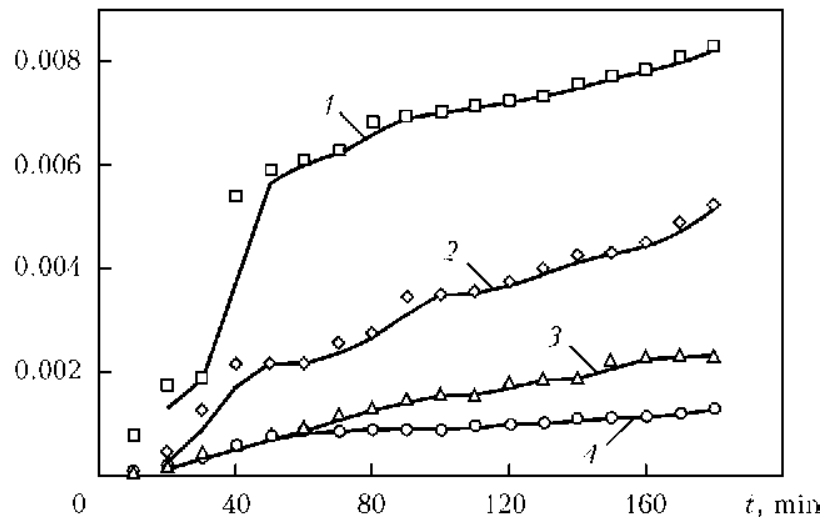

Figure 4. Wear resistance of metal deposited with $25 \mathrm{KhG} 2 \mathrm{~S}$ wire: 1 - initial bead; $2-0.5 \% \mathrm{TiO}_{2} ; 3-0.7 \% \mathrm{Al}_{2} \mathrm{O}_{2}$; $4-90 \% \mathrm{SiO}_{2}$

case of application of silicon dioxide (Figure 4, compare curves 4 and 1 ).

Microhardness measurement showed that at average value for bead initial metal of $H V$ 352, in the other cases microhardness decreased $\left(0.5 \% \mathrm{TiO}_{2}-H V\right.$ 271, $0.7 \% \mathrm{Al}_{2} \mathrm{O}_{3}-$ $H V$ 313), except for $90 \% \mathrm{SiO}_{2}(H V$ 424).

In this case, a correlation between deposited metal hardness and wear resistance is observed. Analysis showed that initial bead metal has bainite structure with a small amount of martensite component (Figure 5, a). Deposited metal with silicon dioxide is characterized by purely martensite structure (Figure 5, b) that, apparently, is exactly what determines wear resistance increase.

Results of analysis of distribution of nonmetallic inclusion quantity revealed that in the initial condition without nanoadditives their volume fraction is equal to $0.25 \%$ and mainly is in the dimensional range of $0.07-0.49 \mu \mathrm{m}$, of which from 12 up to $16 \%$ inclusions correspond to dimensional range of 0.13 to $0.37 \mu \mathrm{m}$.

In the metal of the bead with $0.5 \% \mathrm{TiO}_{2}$ nanooxide the volume fraction of nonmetallic inclusions is somewhat greater and is equal to

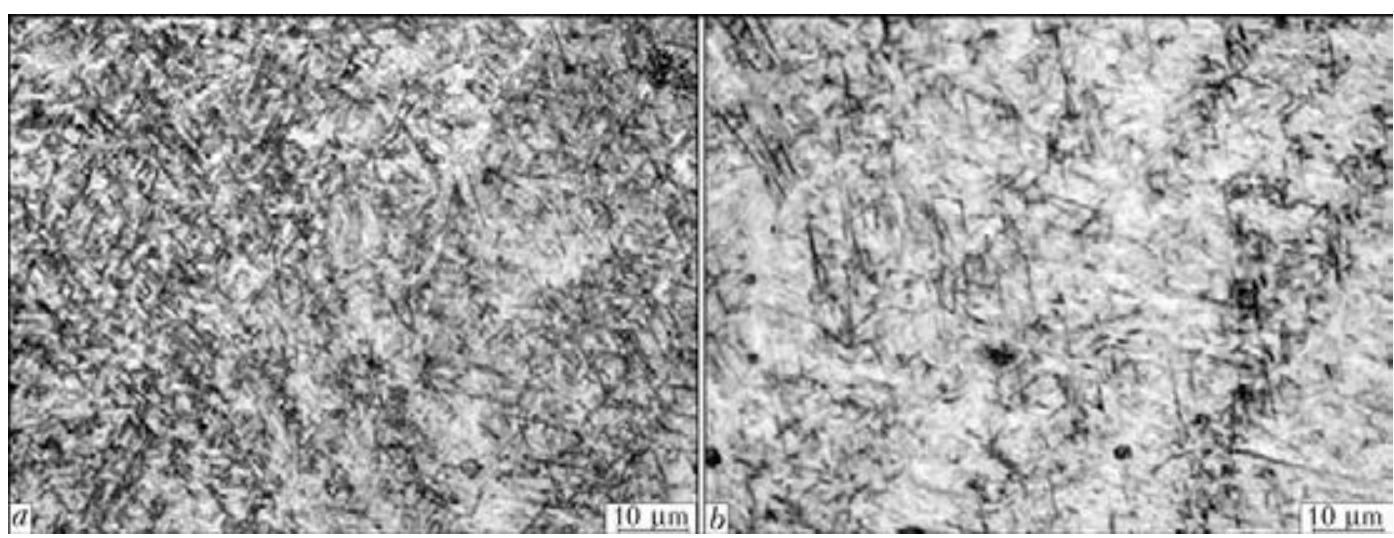

Figure 5. Microstructure of deposited metal without ( $a$ ) and with (b) $\mathrm{SiO}_{2}$ additives 

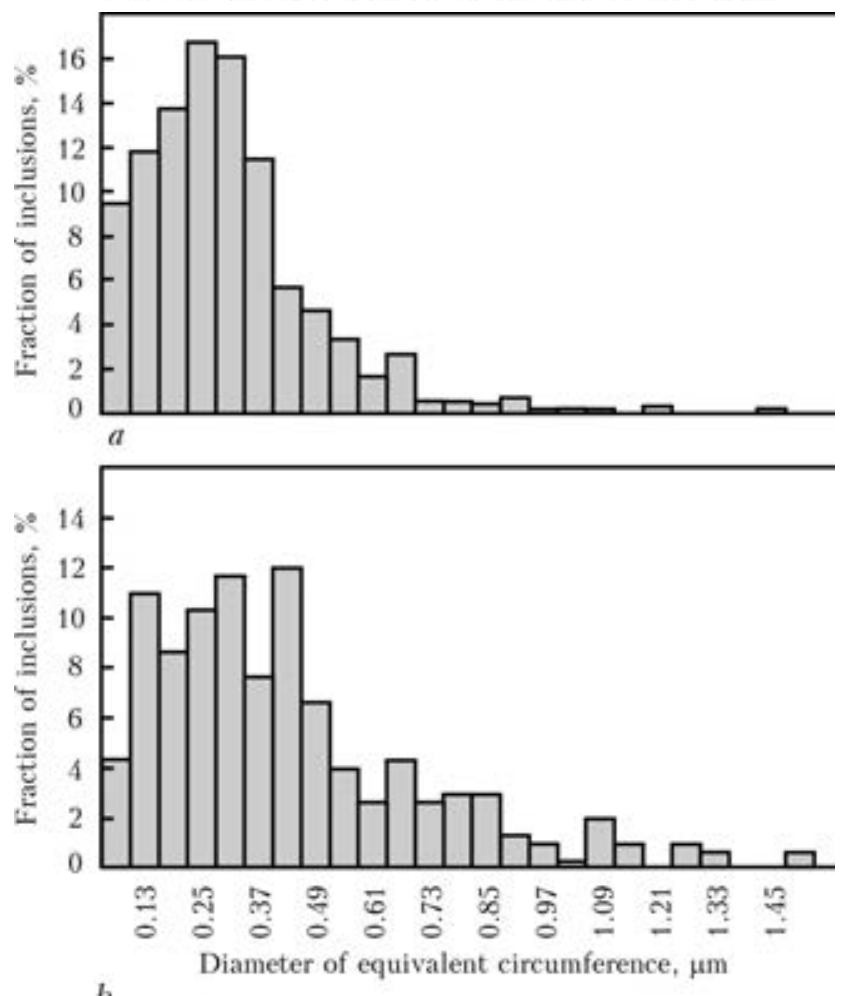

Figure 6. Histogram of inclusion distribution in deposited metal by the parameter of equivalent circumference: $a-$ in the initial condition; $b$ - with $90 \mathrm{vol} . \% \mathrm{SiO}_{2}$ nanooxide

$0.27 \%$, of which from 6 up to $12 \%$ inclusions correspond to dimensional range of $0.07-$ $0.55 \mu \mathrm{m}$.

In the metal of the bead with $0.7 \% \mathrm{Al}_{2} \mathrm{O}_{3}$ nanooxide the volume fraction of nonmetallic inclusions is also greater and is equal to $0.34 \%$, of which from 6 up to $15 \%$ inclusions correspond to dimensional range of 0.07 up to $0.55 \mu \mathrm{m}$.

In the metal of the bead with $90 \% \mathrm{SiO}_{2}$ nanooxide the volume fraction of nonmetallic inclusions is smaller and is equal to $0.2 \%$, of which from 4 up to $12 \%$ inclusions are in the dimensional range of $0.07-0.85 \mu \mathrm{m}$.

Comparative analysis of the data points to an increase of volume fraction of inclusions in the dimensional range of $0.07-0.55 \mu \mathrm{m}$ at feeding nanooxides of both aluminium and titanium and

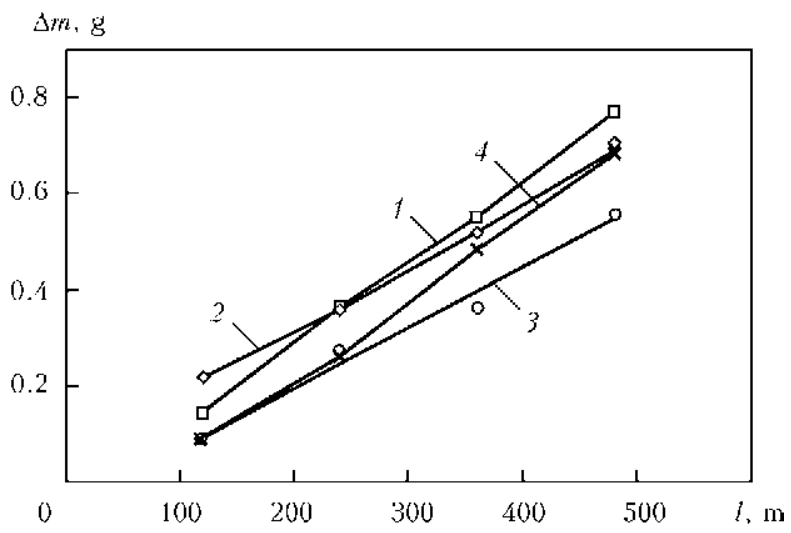

Figure 7. Wear resistance of metal deposited with PP-AN180 wire with feeding nanopowders through powder materials: $1-$ initial bead; $2-\mathrm{Fe}+0.5 \% \mathrm{Al}_{2} \mathrm{O}_{3} ; 3-\mathrm{Fe}+$ $+5 \% \mathrm{Al}_{2} \mathrm{O}_{3} ; 4-\mathrm{Fe}+0.5 \% \mathrm{Al}_{2} \mathrm{O}_{3}$

in greater dimensional range of $0.07-0.85 \mu \mathrm{m}$, respectively, at aerosil feeding, compared to the initial structure.

The established regularities are also confirmed by the results of processing the dimensions of inclusions of just spherical shape by the parameter of equivalent circumference diameter. For instance, Figure 6 gives the histograms by volume fraction and distribution of such inclusions in the weld metal for the initial condition and in the presence of silicon nanooxide.

Processing the dimensions of inclusions of just spherical shape by the parameter of equivalent circumference diameter showed that in the initial condition without nanooxide powder feeding the main part of spherical inclusions from 9 up to $16 \%$ is both in the dimensional range up to $0.3 \mu \mathrm{m}$ and in the ranges of $0.3-0.5 \mu \mathrm{m}$ (Figure $6, a$ ).

At addition of powder of $90 \% \mathrm{SiO}_{2}$ nanooxide, the fraction of spherical inclusions both of up to $0.3 \mu \mathrm{m}$ size and in the range of $0.3-0.5 \mu \mathrm{m}$ rises up to $12 \%$. Here, presence of inclusions of more than $0.8 \mu \mathrm{m}$ size is observed (Figure $6, b$ ). The fact of nonmetallic inclusions coarsening in this case can be associated with increased concentration of aerosil nanoparticles, promoting their coagula-

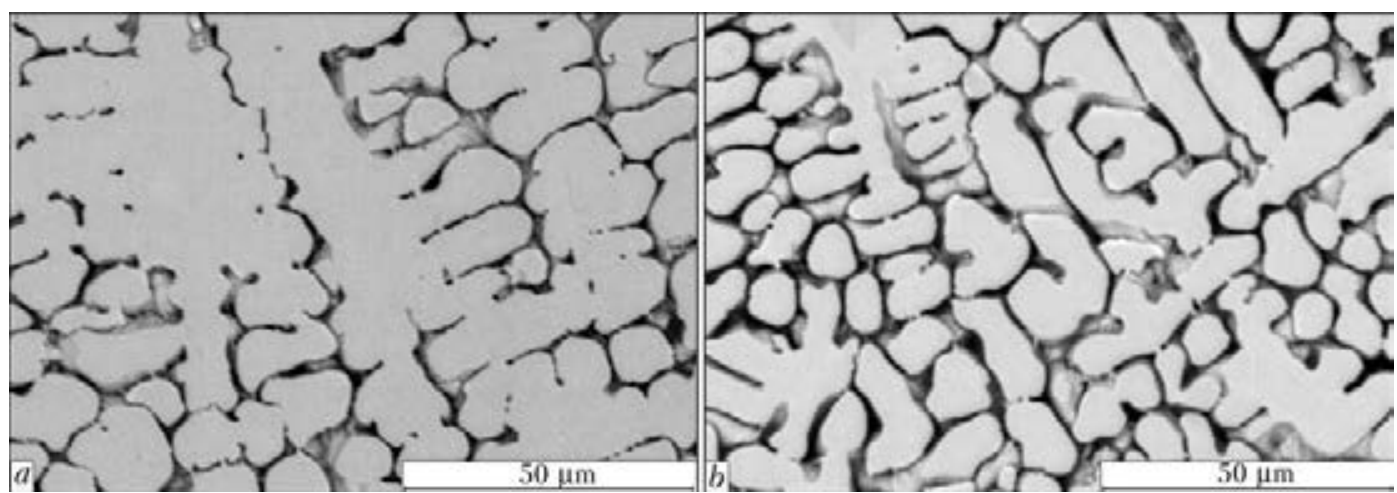

Figure 8. Microstructure of deposited metal without $(a)$ and with $(b) \mathrm{Al}_{2} \mathrm{O}_{3}$ additives 
tion and coalescence with nonmetallic inclusions of material during weld pool solidification.

Testing of the composition of high-chromium cast iron at surfacing with PP-AN-180 flux-cored wire showed that at $0.5 \%$ volume fraction, feeding titanium and aluminium nanooxides has practically the same effect on wear resistance with its slight increase (Figure 7, curves 1, 4, 2). In these experiments wear resistance increase by 1.4 times was observed at feeding $5 \% \mathrm{Al}_{2} \mathrm{O}_{3}$.

Analysis showed that in the initial bead the structure of hypereutectic cast iron is characterized by quite coarse cementite precipitates in the austenitic matrix (Figure 8, $a$ ). In the case of application of $5 \% \mathrm{Al}_{2} \mathrm{O}_{3}$, a significant dispersion of cementite precipitates is observed, that, apparently, is exactly what determines increase of wear resistance of such a structure.

Thus, investigations showed that irrespective of the used alloying systems of surfacing materials or surfacing conditions, the common feature is the positive influence of nanooxides on deposited metal wear resistance. At this research stage it does not seem possible to make unambiguous conclusions on either the mechanism of manifestation of the positive effect of nanooxide application, or their volume fraction for different surfacing conditions, that neccessitates further studies.

\section{Conclusions}

1. Positive influence of volume ratios of aluminium and titanium nanooxides on wear resistance, earlier established for low-alloyed steel welds, was confirmed at deposition of high-chromium compositions with increased carbon content. It is established that silicon nanooxide is a more effective nanoadditive for these compositions.

2. At deposition of medium-alloyed composition, it is further established that silicon dioxide is more effective compared to aluminium and titanium nanooxides, providing a more than 4 times increase of wear resistance.
3. For abrasive wear conditions at deposition of high-chromium cast iron composition, the effect of wear resistance increase is manifested to a smaller degree (by $40 \%$ ), compared to compositions recommended for metal-to-metal friction conditions.

1. Ryabtsev, I.A. (2004) Surfacing of machine and mechanism parts. Kiev: Ekotekhnologiya.

2. Ryabtsev, I.A., Senchenkov, I.K. (2013) Theory and practice of surfacing operations. Kiev: Ekotekhnologiya.

3. Lee, T.K., Kim, H.J., Kang, B.Y. et al. (2000) Effect of inclusion size on the nucleation of acicular ferrite in welds. ISIJ Int., 40, 1260-1268.

4. Golovko, V.V., Grigorenko, G.M., Kostin, V.A. (2011) Effect of nanoinclusions on structure formation of weld metal of ferritic-bainitic steels (Review). Zbirnyk Nauk. Prats NUK, 4, 42-49.

5. Golovko, V.V., Stepanyuk, S.M., Ermolenko, D.Yu. (2012) Investigation of effect of nanoformations in metal on weld microstructure formation and its mechanical properties. In: Building, materials science, machine-building, Issue 64, 155-159.

6. Golovko, V.V., Pokhodnya, I.K. (2013) Effect of non-metallic inclusions on formation of structure of the weld metal in high-strength low-alloy steels. The Paton Welding J., 6, 2-10.

7. Vanovsek, W., Bernhard, C., Fiedler, M. et al. (2013) Influence of aluminium content on the characterization of microstructure and inclusions in highstrength steel welds. Welding in the World, 57(1), 73-83.

8. Junseok Seo, Heejin Kim, Changhee Lee (2013) Effect of $\mathrm{Ti}$ addition on weld microstructure and inclusion characteristics of bainitic GMA welds. ISIJ Int., 53(5), 880-886.

9. Yushchenko, K.A., Ustinov, A.I., Zadery, B.A. et al. (2010) Effect of nanofoil of $\mathrm{Ni}-\mathrm{NbC}$ system on structure of electron beam welds in heat-resistant alloys. The Paton Welding J., 11, 2-7.

10. Kuznetsov, V.D., Smirnov, I.V., Stepanov, D.V. et al. (2013) Effect of modification by oxide nanoparticles on structure formation of low-alloy steel welds. Mizhouz. Zbirnyk Naukovi Notatky, 41, Pt 2, 61-68.

11. Kuzniecow, W., Szapowalow, K. (2014) Effect of nano-oxides on the structure and properties of low-alloy steel weld metal. Biuletyn Institutu Spawalnictwa , 5, 103-108.

12. Knyazkov, K.V., Radchenko, M.V., Smirnov, A.N. et al. (2012) Increase in properties of plasma-powder coatings by their modification with nanosized particles. Polzunovsky Vestnik, 1, 127-130.

13. Sokolov, G.N., Lysak, I.V., Troshkov, A.S. et al. (2009) Modification of deposited metal structure by nanodispersed tungsten carbides. Fizika $i$ Khimiya Obrab. Materialov, 6, 41-47.

Received 12.05.2015 